\title{
Parathyroid Hormone: Is It Really the Cause for Increased Tooth Mobility after Orthognathic Surgery?
}

\author{
Nezar Watted ${ }^{*}$, Emad Hussein ${ }^{1}$, Muhamad Abu-Mowais ${ }^{1}$, Azzaldeen Abdulgani' ${ }^{2}$, \\ Peter Proff ${ }^{3}$, Abu-Hussein Muhamad ${ }^{4}$ \\ ${ }^{1}$ Department of Orthodontics, Arab American University, Jenin, Palestine \\ ${ }^{2}$ Department of Conservative Dentistry, Al-Quds University, Jerusalem, Palestine \\ ${ }^{3}$ Department of Orthodontics, University of Regensburg, Regensburg, Germany \\ ${ }^{4}$ Department of Pediatric Dentistry, University of Athens, Athens, Greece \\ Email: *prof.watted@gmx.net, ${ }^{*}$ nezar.watted@gmx.net
}

Received 4 June 2014; revised 22 July 2014; accepted 6 August 2014

Copyright (C) 2014 by authors and Scientific Research Publishing Inc.

This work is licensed under the Creative Commons Attribution International License (CC BY).

http://creativecommons.org/licenses/by/4.0/

c) (i) Open Access

\begin{abstract}
Introduction: Following orthognathic surgery, increased tooth mobility is observed clinically and is utilized for postsurgical orthodontic tooth movement. It was suggested that the increase may result from a surgery-associated alteration of parathyroid hormone (PTH) and calcium metabolism. Materials and Methods: 30 young adult patients were divided into a mandibular osteotomy group (Group $A, n=20$ ) and an untreated control group (Group B, $n=10$ ). Tooth mobility was evaluated using the Periotest device. Tooth mobility, serum PTH and calcium levels were determined repeatedly for both groups. Results: The tooth mobility was increased significantly in the Group A patients in the first 10 days post-surgery. All serum PTH and calcium mean levels were within normal ranges. No significant differences were found between the measurements of both groups. The serum calcium levels recorded at the 1st post-surgery day were slightly lower in the operated patients compared to the control group. Conclusion: It can be concluded that the increased facility of orthodontic tooth movement immediately post-surgery was confirmed by Periotest measurements, while no association was found with surgery-related altered levels of PTH and calcium. Since dietary effects can be ruled out, the increase of clinical tooth mobility may rather result from preoperative orthodontic forces and/or the post-surgical elimination of masticatory muscular influences.
\end{abstract}

\section{Keywords}

Orthognathic Surgery, Parathyroid Hormone (PTH), Calcium Concentration, Tooth Mobility

${ }^{*}$ Corresponding author.

How to cite this paper: Watted, N., Hussein, E., Abu-Mowais, M., Abdulgani, A., Proff, P. and Muhamad, A.-H. (2014) Parathyroid Hormone: Is It Really the Cause for Increased Tooth Mobility after Orthognathic Surgery? Open Journal of Stomatology, 4, 424-433. http://dx.doi.org/10.4236/ojst.2014.48057 


\section{Introduction}

The possible influence of Parathyroid Hormone (PTH) induced changes of bone metabolism on tooth mobility has been discussed for over 30 years [1] [2]. It had been reported that continuous PTH administration resulted in an increased bone resorption rate which accelerated tooth mobility up to 2 to 3 times [3].

PTH is produced in the parathyroid glands. Its purpose is to keep the serum calcium level constant (8.5 - 10.5 $\mathrm{mg} / 100 \mathrm{ml}$ or $2-2.7 \mathrm{mmol} / \mathrm{l})$. Its synthesis and release are regulated by the plasma concentration of calcium. It increases the synthesis of 1,25-Dihydroxyvitamin D3, which stimulates the intestinal resorption of calcium and phosphor as well as the bone resorption. PTH has an indirect influence on the number and activity of osteoclasts. A long term excess of PTH increased bone loss, as observed in primary hyperparathyroidism patients who showed approximately a $10 \%$ decrease in bone density [4].

Boabaid et al. suggested that parathyroid hormone-related protein (PTHrP) might have a significant impact on osteoclastogenesis, root resorption, and tooth eruption [5]. Others have discussed the anabolic and catabolic potential effect of PTH mediated by osteoblast-like cells in the PDL [6]-[8].

It was hypothesized that the clinically observed increased tooth mobility after orthognathic surgery could be attributed to an increased bone-turnover-rate related to postsurgical increased PTH levels [9]. This hypothesis was tested in a multi-disciplinary Orthodontic-Nuclear Medicine study as part of research of combined orthodontic-surgery therapy of Class II deformities [10].

The aim of this prospective study was to evaluate the post orthognathic surgery PTH levels and their influence on post-surgical tooth mobility.

\section{Mechanism of Hormone Action}

The function of parathyroid is to maintain a normal level of diffuse calcium and phosphorus in the blood plasma and to keep constant the ratio of these minerals to each other. The act as a check on the thyroid gland parathyroids are important organs in ca metabolism and play a leading role in calcification of teeth. However, once the teeth are formed, there is no evidence found of calcium withdrawal from teeth due to parathyroid disturbances. The parathyroids are important in regulating blood ca level, but have little or no direct effect on growth or tooth eruption.

PTH affects osteoblasts' cellular metabolic activity, gene transcriptional activity, and multiple protease secretion. Its effects on osteoclasts occur through the production of RANK-L receptor (activator of nuclear factor kappa-B ligand), a protein playing a crucial role in osteoclasts' formation and activity. In 1970s, animal studies demonstrated that PTH could induce an increase in bone turnover that would accelerate orthodontic tooth movement. More recently, an increased rate of tooth movements has been observed in rats treated with PTH, whether administered systemically or locally. These results indicate that orthodontists should take note of patients being treated with PTH, as for example, in cases of severe osteoporosis.

Parathyroid hormone (PTH) affects both bone resorption and formation process. If PTH appears around bone cells, the effect of bone will be resorption. By contrast, low level of PTH results in bone formation. When the calcium level in blood decreases, PTH will stimulate osteoclastic activity to increase calcium and phosphate absorption in the gut, and decrease calcium excretion and tubular phosphate reabsorption in the kidney. This plays a role as regulator of calcium homeostasis by PTH.

\section{Combined Orthodontic and Orthognathic Surgical Therapy}

One of the main objectives of orthodontics, in addition to the diagnosis of dysgnathia, is to determine the status of indication for orthodontic treatment, for which treatment, necessity, and prognosis are evaluated.

Occlusion, function, and aesthetics are considered equivalent parameters in modern orthodontics, particularly in combined orthodontic and orthognathic surgical treatment. This was achieved through the optimisation of diagnostic tools and advancements and increasing experience in orthopaedic surgery.

The objectives of orthodontic and orthognathic surgical treatments are the:

1) establishment of a neutral, stable and functional occlusion with physiological condylar positioning;

2) optimisation of facial aesthetics;

3) optimisation of dental aesthetics, considering the periodontal situation;

4) assurance of the stability of the results achieved; and 
5) fulfilment of the patient's expectations.

In many cases, the objectives of dentoalveolar treatment measures are the achievement of the functional and aesthetic optimum for the patient, which can be achieved using modern treatment methods. While minor dysgnathias can be treated using only dentoalveolar measures, successful treatment of prominent sagittal discrepancies, such as Class II dysgnathias, is far more difficult. Correction can be achieved through dental movement if the jaw proportion is correct and if the dysgnathia is purely dentoalveolar. However, dental movements are possible only up to a certain degree and are thus limited. A correction or stable dental compensation of a skeletal dysgnathia (for example, the correction of a frontal cross-bite in a Class III or the correction of an extremely enlarged sagittal overjet in a Class II) is doubtful in some cases and, in general shows a compromise in aesthetics and/or function.

In order to determine the options available for the therapy of a Class II dysgnathia, the remaining growth of the patient must be determined. Functional orthodontic treatment is a therapy form that can influence growth and is considered a causal therapy in adolescents. If there is no growth therapeutically, orthognathic surgery to correct the position discrepancy between both jaws is a causal therapy form.

A premise for the successful realisation of a combined therapy is that less invasive treatment options (for example, growth influence, as mentioned above) can no longer be used or do not achieve the treatment objectives or even worsen the situation (for example, extraction in a shallow mouth profile or distalisation in a narrow overbite).

The second option for the causal therapy of a skeletal dysgnathia (Class II) using combined orthodontic and orthognathic surgical.

The first orthodontic-maxillofacial procedure on the mandible described in the literature was that of the American surgeon Hullihen in 1848 [11]. This procedure was a segmental osteotomy of the anterior mandible. In 1955 Obwegeser introduced sagittal splitting at the horizontal ramus of the mandible [12]. In 1959, Dal Pont moved the buccal osteotomy line from the last molar to the inferior margin of the mandible [13]. Sence then, this method of sagittal split at the mandible has been called sagittal split according to Obwegeser-Dal Pont. Epker developed the incomplete sagittal split in to a routine method [14].

\section{Materials and Methods}

A total of 30 healthy young patients participated in this study. 20 patients were planned to undergo a bilateral sagittal split osteotomy of the mandible (Group A, $n=20,14$ female and 6 male), and 10 patients were chosen to participate in the non-surgery control group (Group B, $n=10,6$ female and 4 male). Group A consisted of patients with a Class II deformity and skeletal deep bite. The mean age of this group was $27.1 \pm 5$ years. Group $\mathrm{B}$ consisted of healthy patients who did not require any surgical intervention. The mean age of this group was $28.5 \pm 2$ years.

The therapeutic approach was chosen according to the Würzburg Treatment Concept for orthognathic surgery cases with a class II deformity and skeletal deep bite-short face syndromes [10]. All Group A patients underwent a sagittal split osteotomy according to Obwegeser-Dal Pont. Fixation of the two segments after the osteotomy was achieved with rigid screw fixation. The posterior rotation of the tooth bearing segment during surgery with its 3-point contact, and the opening of the gonion-angle produced a lengthening of the lower face. A consequence of this procedure is a lateral open bite which has to be closed by orthodontic means as soon as possible after surgery (Figures 1-10).

PTH and serum calcium concentration of Group A were measured by drawing $10 \mathrm{ml}$ of venous blood one day before surgery, and 1, 10 and 28 days after surgery. Serum concentration of intact, biological active parathyroid hormone was measured with an immunoassay. The physiologic parathyroid hormone was set between 10 and 65 $\mathrm{pg} / \mathrm{ml}$ [15]. In an identical manner, serum concentration of PTH and calcium were measured under standardized conditions for the patients of Group B during a ten-day period on the first, second, third and tenth day.

Tooth mobility was measured with the Periotest-appliance (Medizintechnik Gulden e. K., Modautal, Germany) [16] prior to initiation of orthodontics in Group A and in the same sessions of blood drawing in both groups. The first measurements were taken as baseline values and were set to zero. The technique for dynamically diagnosing the parodont makes use of an electronically controlled reproducible percussion of the teeth: Short shocks of $0.2 \mathrm{~m} / \mathrm{s}$ velocity with the tip of the handpiece are applied perpendicular to the crown of the tooth, and the give way of the tooth is electronically measured. The Periotest-value (PTV) is calculated from the signal of the 


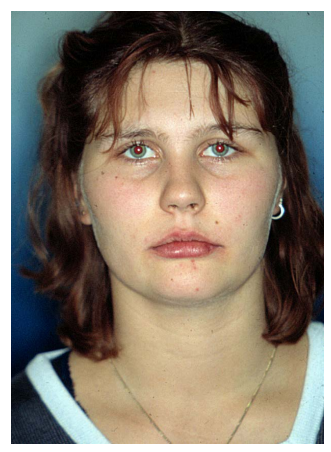

(a)

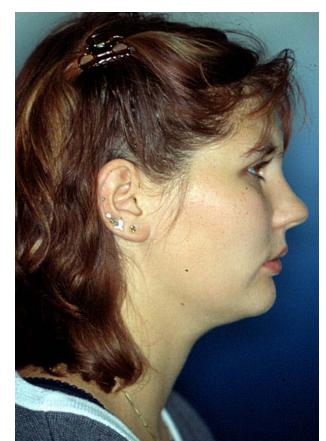

(b)

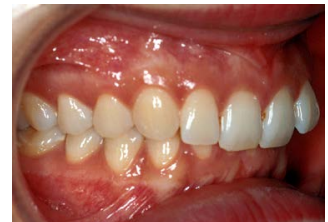

(c)

Figure 1. (a), (b) Anterior and lateral photostat picture of female class II patient with skeletal deep bite, short-face-syndrome", short lower face, deepened sublabial sulcus with prominent lower lip and chin. (c) Intraoral views in centric relation, distal occlusion.

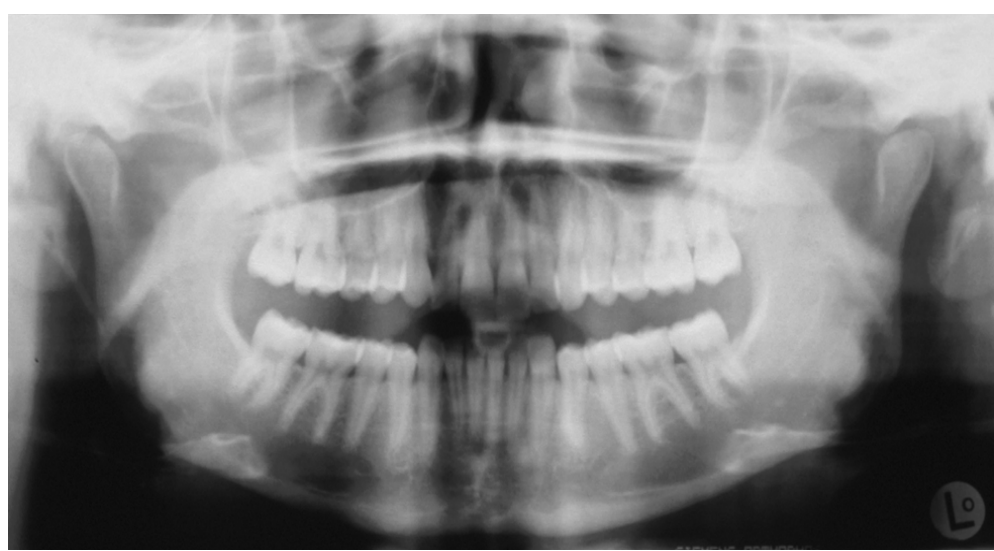

Figure 2. Orthopantomogram (OPG) at the beginning of treatment.

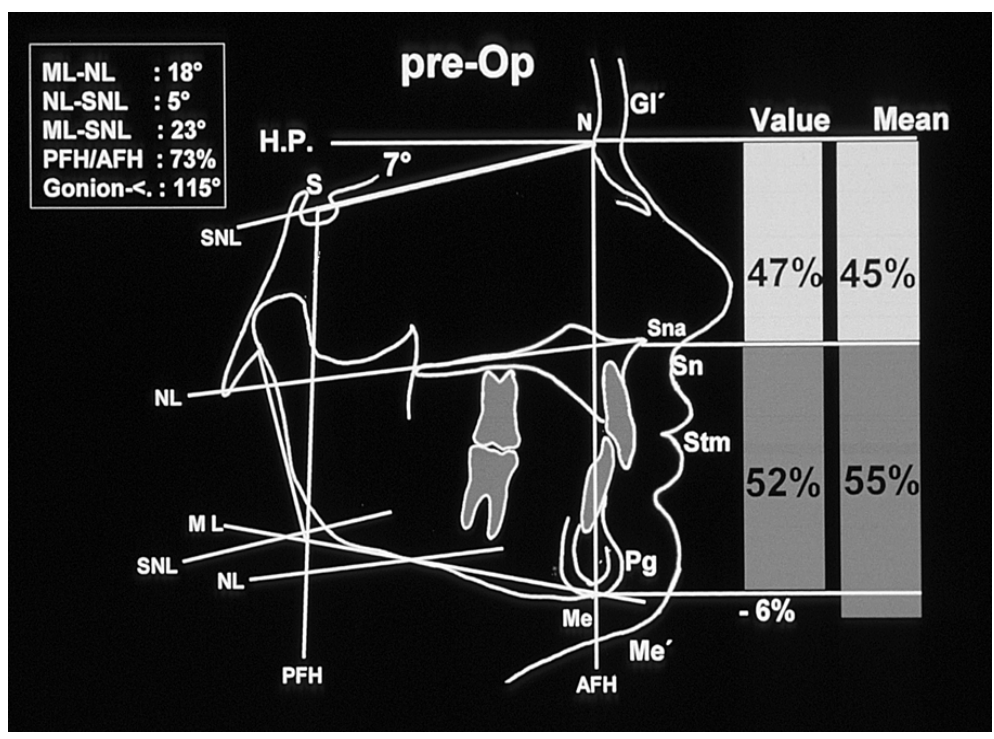

Figure 3. Tracings of the lateral cephalogram prior to treatment; there is a soft tissue and skeletal disharmony in the vertical proportion of the hard and soft tissue: compared to the lower face the upper face is increased by $6 \%$ (hard tissue: N-Sna:Sna-Me = 47\%:53\%). 


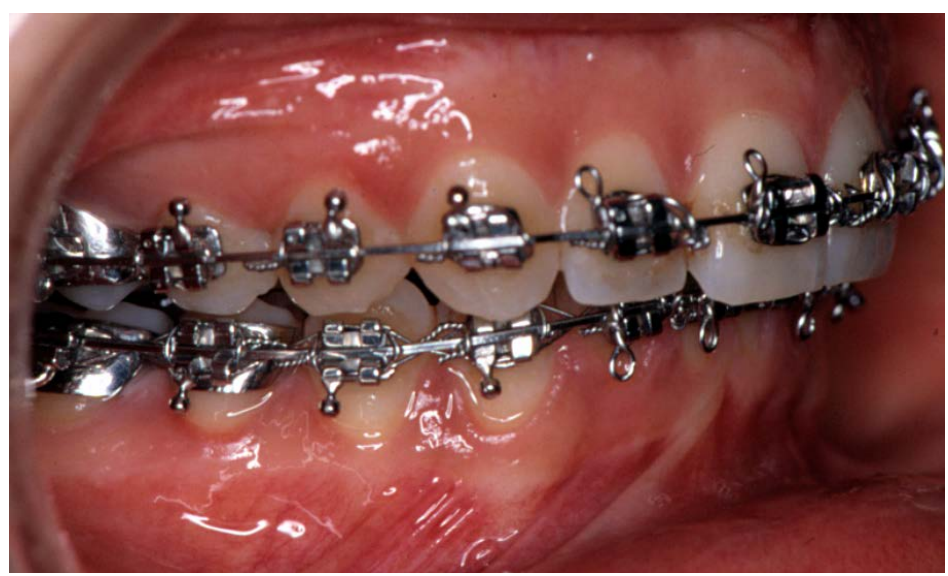

Figure 4. Intraoral view for the surgery.

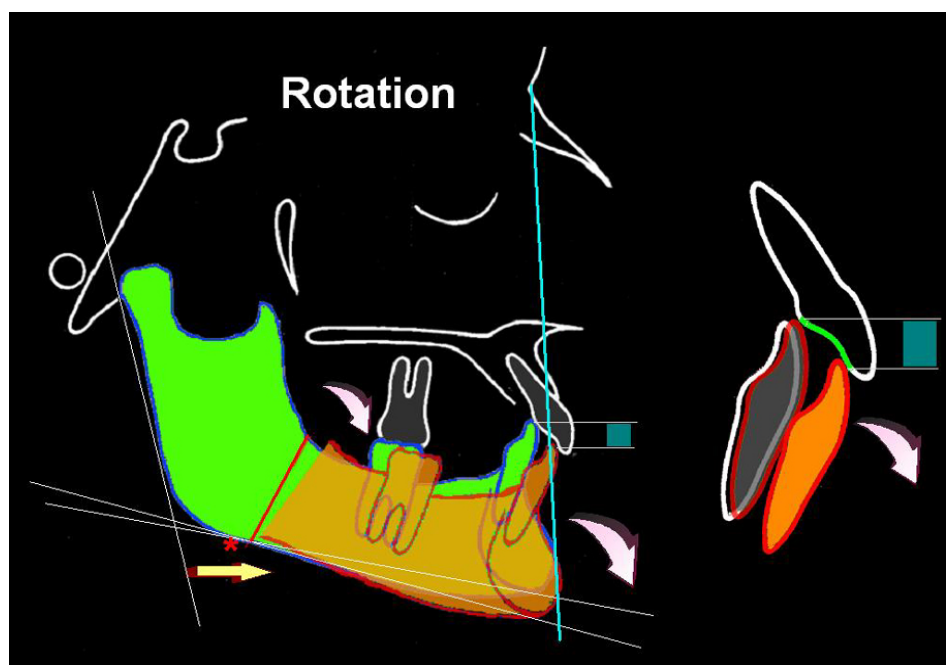

Figure 5. Simulation of the surgical mandibular advancement for the correction of Cl. II, a posterior rotation of the horizontal mandibular segment during surgical advancement of the mandible depends upon a 3-point contact to the anterior teeth and molars. To obtain this 3-point-contact, it is necessary to keep the curve of spee. With the rotation, the menton is displaced caudally and the skelettal and soft tissue situation of the lower face is improved in the vertical dimension. Because of the posterior rotation the chin is displaced ventral only slightly which is benefitial for the profile of these patients. The mentolabial sulcus is flattened.

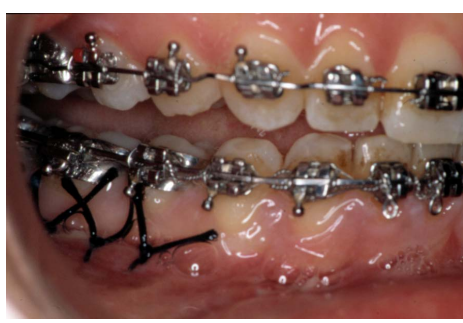

(a)

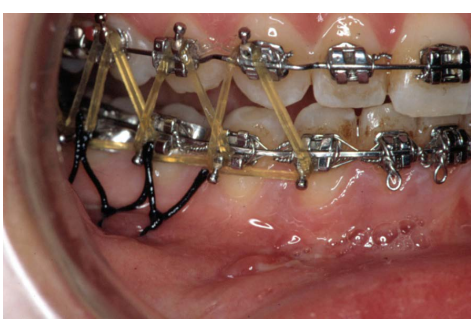

(b)

Figure 6. (a) As a consequence of the posterior rotation of the segment with 3-point contact, a laterally open bite results after surgery. (b) Application of orthodontic forces after surgery for the correction of the lateral open bite. 


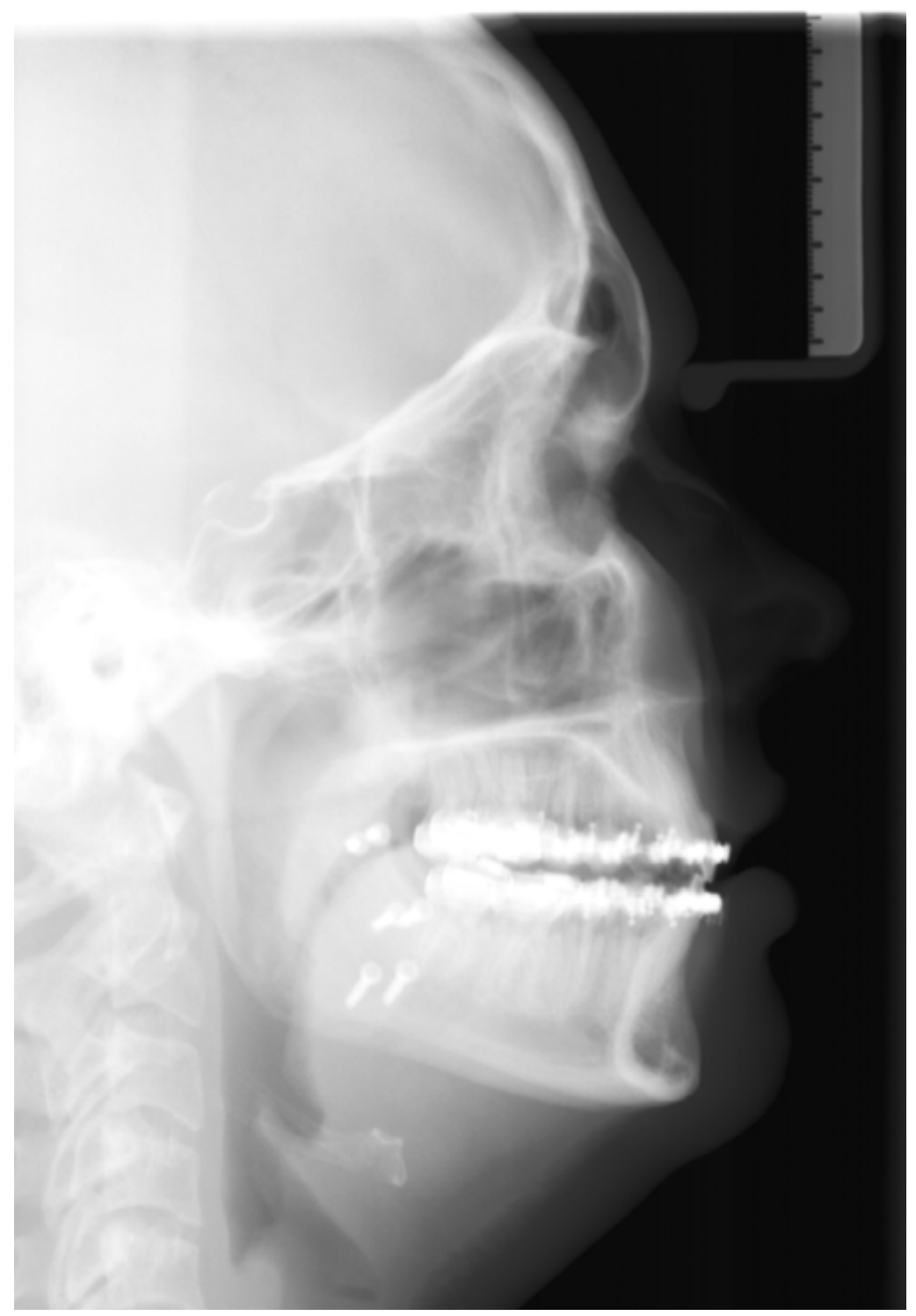

Figure 7. Cephalogram 3 days after the surgery.

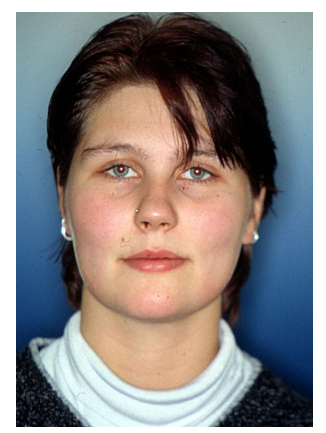

(a)

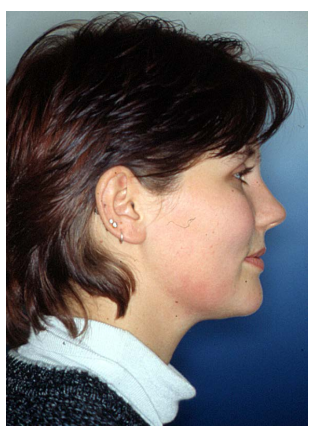

(b)

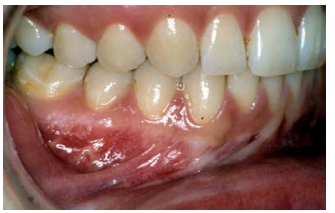

(c)

Figure 8. (a), (b) Extraoral picture: sagittal correction without increasing chin prominence, harmonization of vertical dimension, relaxation of mentolabial sulcus; (c) Intraoral view after surgical correction of the deformity and post surgery finishing of the occlusion. 


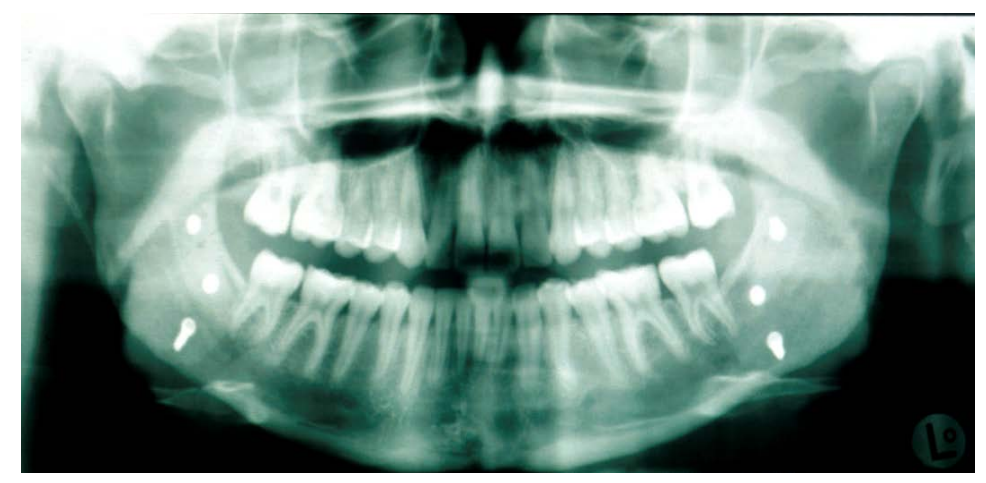

Figure 9. Orthopantomogramm after treatment.

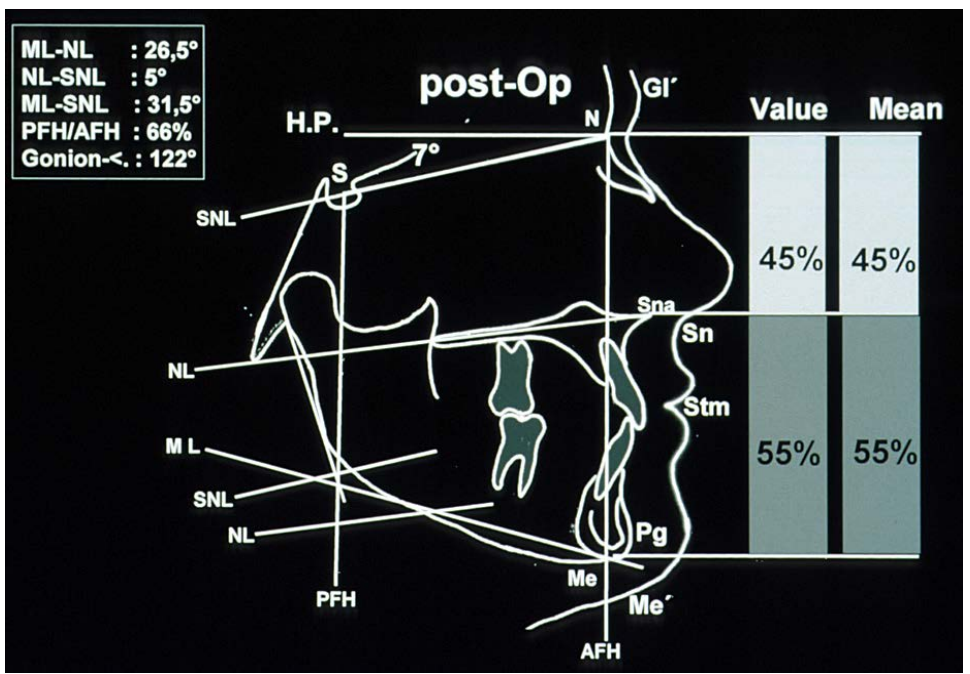

Figure 10. Lateral cephalogram: harmonious soft-tissue relation between upper and lower face, sagittal and vertical harmonization of skeletal structures.

acceleration measure and represents a biophysical value. It is a valid indicator for measuring tooth mobility [17] (Figure 11(a), Figure 11(b)).

Intra-group comparisons between the measurements were statistically tested for differences with the Friedman Rank Analysis or Wilcoxon's test; inter-group differences were tested with the Kruskal-Wallis H-test or the Mann-Whitney U-Test with a level of significance of 5\%.

\section{Results}

In the orthognathic surgery group (A), tooth mobility was increased significantly between the measurements. The average of all measured teeth (without second and third molars) was increased by about 5.5 PTV (mean value 12 PTV) during the first 4 days after surgery and by another 6.6 PTV (18.6 PTV) on the 10th day post surgery point. Four weeks after surgery tooth mobility decreased by 8.4 PTV (10.2 PTV). The differences between consecutive measurements were all found to be significant (Table 1).

PTH concentrations at all times were within norm-values $(10-65 \mathrm{pg} / \mathrm{ml})$. Only six measurements (of five patients) were slightly below the norm (between 7.5 and $8.9 \mathrm{pg} / \mathrm{ml}$ ). There were no significant differences (Table 2 and Table 3) between the measurements. All values of serum calcium concentration were within the norm of $2 / 0-2 / 7 \mathrm{mmol} / \mathrm{l}$. Here, too, no significant differences between the measurements were found.

The mean values of PTH and calcium serum concentration of the surgery group (A) as well as the mean increase of tooth mobility from pre-surgery to 28 days post-surgery can be found in Figure 12.

In the non-treated subjects (Group B) no change in tooth mobility could be observed (Table 1). All PTH concentrations were within the norm of 10 to $65 \mathrm{pg} / \mathrm{ml}$. In only three subjects measurements were slightly above 


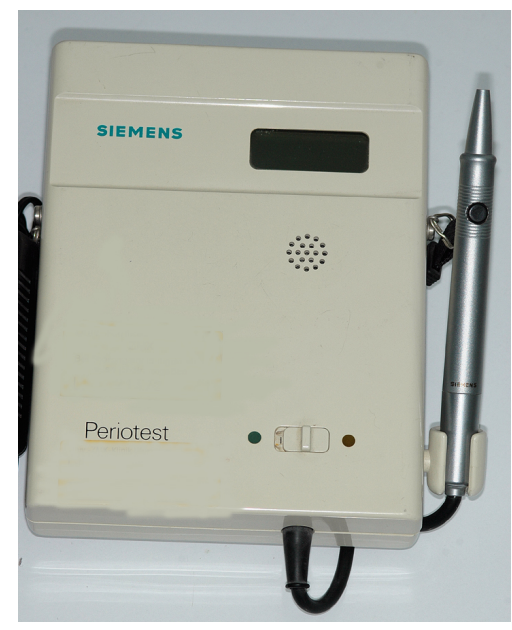

(a)

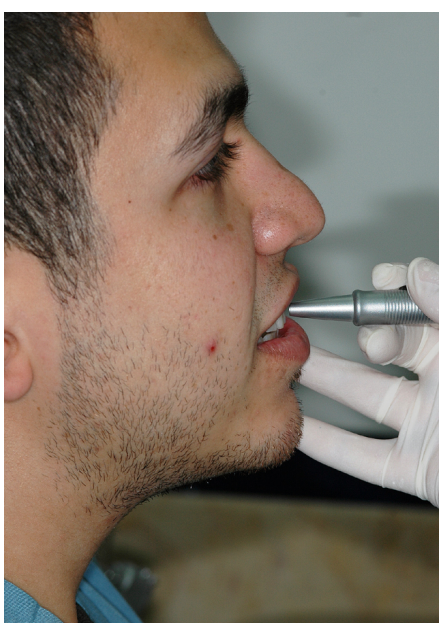

(b)

Figure 11. (a), (b) The handpiece of the periotest-appliance positioned to an anterior tooth. During measurements the handpiece has to be hold perpendicular to the long-axis of the tooth at the middle of the crown. An acoustic computer signal shows inacceptable deviations.

Table 1. Changes of the periotest-values of all measured teeth in Group A (surgery) and B (control).

\begin{tabular}{|c|c|c|c|c|c|}
\hline \multicolumn{6}{|c|}{ Changes of tooth mobility (periotest-value) } \\
\hline \multicolumn{3}{|c|}{ Surgery-group (Gr. A) } & \multicolumn{3}{|c|}{ Control-group (Gr. B) } \\
\hline PVT & Mean \pm standard dev. & Minimum/maximum & Minimum/maximum & Mean \pm standard dev. & PVT \\
\hline Pre-orthod. & $+0.0 /+0.0$ & $+0.0 /+0.0$ & & & \\
\hline 1 day pre-OP & $+6.5 \pm 0.8$ & $+5.4 /+7.9$ & $+0.0 /+0.0$ & $0.0 \pm 0.0$ & 1 day \\
\hline 4 days post-OP & $+12.0 \pm 0.8$ & $+11.1 /+13.2$ & $-0.1 /+0.3$ & $+0.2 \pm 0.2$ & 2 days \\
\hline 10 days post-OP & $+18.6 \pm 2.3$ & $+14.5 /+21.7$ & $-0.2 /+0.3$ & $-0.1 \pm 0.2$ & 3 days \\
\hline 28 days post-OP & $+10.2 \pm 1.6$ & $+7.8 /+12.8$ & $-0.1 /+0.3$ & $+0.1 \pm 0.2$ & 10 days \\
\hline
\end{tabular}

Table 2. PTH concentration in the surgery (A) and control (B) group.

\begin{tabular}{cccccc}
\hline & Surgery-group (Gr. A) & \multicolumn{3}{c}{ Control-group (Gr. B) } \\
\hline $\mathbf{~ p g} / \mathbf{m l}$ & Mean \pm standard dev. & Minimum/maximum & Minimum/maximum & Mean \pm standard dev. & pg/ml \\
\hline 1 day pre-OP & $28.99 \pm 15.3$ & $13.1 / 59.5$ & $12.7 / 71.9$ & $32.71 \pm 18.6$ & 1 day \\
4 days post-OP & $29.67 \pm 17.8$ & $8.7 / 65.5$ & $10.6 / 72.5$ & $32.63 \pm 18.6$ & 2 days \\
10 days post-OP & $22.99 \pm 18.1$ & $7.5 / 69.6$ & $10.2 / 74.5$ & $28.93 \pm 17.4$ & 3 days \\
28 days post-OP & $25.49 \pm 15.0$ & $8.9 / 71.9$ & $11.3 / 29.1$ & $28.05 \pm 17.6$ & 10 days \\
\hline
\end{tabular}

Table 3. Calcium concentration in the surgery (A) and control (B) group.

\begin{tabular}{|c|c|c|c|c|c|}
\hline \multicolumn{3}{|c|}{ Surgery-group (Gr. A) } & \multicolumn{3}{|c|}{ Control-group (Gr. B) } \\
\hline mmol/l & Mean \pm standard dev. & Minimum/maximum & Minimum/maximum & Mean \pm standard dev. & mmol/l \\
\hline 1 day pre-OP & $2.39 \pm 0.087$ & $2.23 / 2.55$ & $2.24 / 2.48$ & $2.32 \pm 0.079$ & 1 days \\
\hline 4 days post-OP & $2.20 \pm 0.117$ & $2.04 / 2.45$ & $2.11 / 2.37$ & $2.30 \pm 0.072$ & 2 days \\
\hline 10 days post-OP & $2.38 \pm 0.079$ & $2.24 / 2.56$ & $2.27 / 2.52$ & $2.37 \pm 0.067$ & 3 days \\
\hline 28 days post-OP & $2.38 \pm 0.093$ & $2.19 / 2.57$ & $2.26 / 2.46$ & $2.36 \pm 0.060$ & 10 days \\
\hline
\end{tabular}




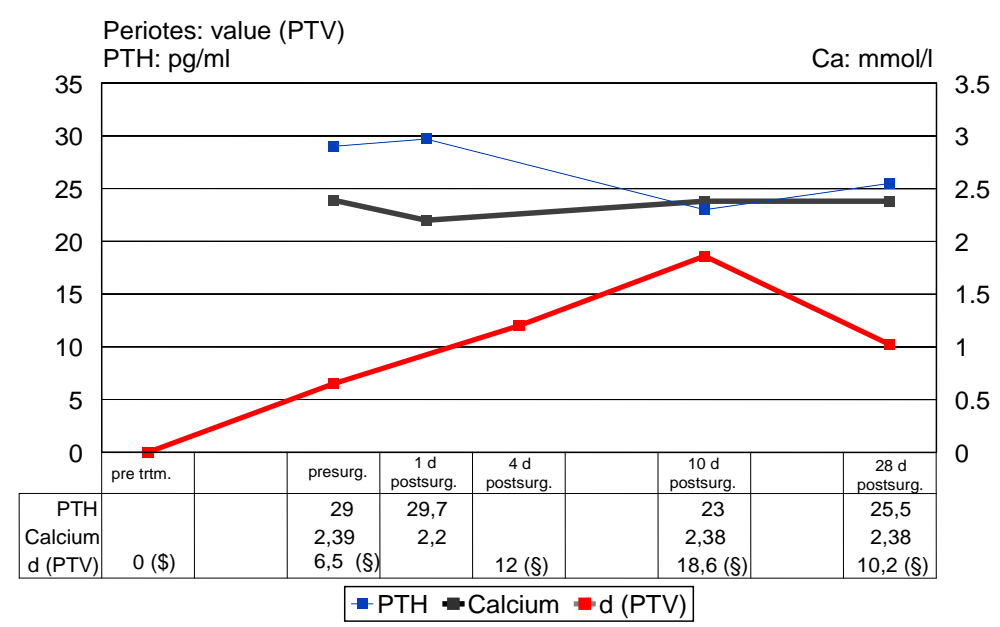

Figure 12. Mean serum concentration of PTH and calcium and mean increase of tooth mobility from pre-surgery to 28 days after surgery in the surgery group. (\$) set to 0 to control the different baseline tooth mobilities of the different teeth. This value is the mean of all measured teeth. (§) Significant differences compared to the previous measurement.

the norm (max. $74.5 \mathrm{pg} / \mathrm{ml}$ ) and were considered outliers. When discarding these values, no significant difference could be detected between the measurements (Table 2, Figure 3). Again, all serum calcium concentrations were within the norm of $2.0-2.7 \mathrm{mmol} / \mathrm{l}$ and no statistically significant differences could be detected between the measurements (Table 3, Figure 3).

Concerning PTH-no differences between the groups could be detected. Serum calcium concentrations were slightly decreased in the surgery group $(2.17 \pm 0.12)$ on the first day after surgery compared to the control group ( $2.27 \pm 0.07, \mathrm{p}=0.06$ ), though these differences were only marginally significant.

\section{Discussion}

During orthodontic tooth movement, bone remodeling process is related to the expression of mediators. Acute inflammatory response is presented in the early phase of orthodontic tooth movement. Inflammatory mediators may stimulate the biological processes that associated with alveolar bone resorption and deposition. Furthermore, orthodontic forces can induce the bone remodeling process by the local mediators, such as prostaglandins, cytokines and growth factors, that play an important role in bone remodeling. PGE2 has been involved in bone remodeling and especially recognized as a potent stimulator of bone resorption.

The measurements of the Periotest appliance revealed an obvious increase in tooth mobility in the orthognathic surgery patients. However, there was no correlation between this increased tooth mobility and elevated serum concentration of PTH and calcium. The changes in calcium concentration during and after orthognathic surgery were within $20 \%$ of the pre-surgery values. The variability of these measurements among the nontreated subjects (Group B) was within $\pm 15 \%$. A slight decrease of serum calcium on the first day after surgery was accompanied by a slight reactive increase in PTH concentration, though these changes were not significant.

Patients scheduled for orthognathic surgery are usually young healthy individuals. Possible metabolism disturbances, insufficient kidneys or maldigestion should be excluded in the pre-surgery examination. In-patient post-surgical diet generally protects the patients from a nutritionally based calcium deficiency. Although secondary hyperparathyroidism after large scale surgical procedures has been proven to cause tooth mobility and other dental symptoms both in animals and humans [16] [18] [19], these obviously cannot be caused solely by a surgical procedure of the extent of a osteotomy of the mandible.

The increased tooth mobility observed after orthognathic surgery might be explained by the orthodontic forces which are sometimes applied until just before surgery, exaggerated by repeated intermaxillary fixations as well as the postsurgical elimination of masticatory muscular influences.

Nevertheless, it is our opinion that parathyroid hormone and its influence on accelerated orthodontic tooth mobility should be the focus of further research. 


\section{Conclusion}

The clinically observed increased tooth mobility after orthognathic surgery could be confirmed with the use of the Periotest system. No association was found between tooth mobility and surgery-related altered levels of PTH and calcium. The increase of clinical tooth mobility may rather result from pre-surgery orthodontic forces and/or the post-surgical elimination of masticatory muscular influences on occlusion.

\section{References}

[1] Gianelly, A.A. and Schnur, R.M. (1969) The Use of Parathyroid Hormone to Assist Orthodontic Tooth Movement. American Journal of Orthodontics, 55, 305-312. http://dx.doi.org/10.1016/0002-9416(69)90114-6

[2] Midgett, R.J., Shaye, R. and Fruge Jr., J.F. (1981) The Effect of Altered Bone Metabolism on Orthodontic Tooth Movement. American Journal of Orthodontics, 80, 256-262. http://dx.doi.org/10.1016/0002-9416(81)90289-X

[3] Soma, S., Iwamoto, M., Higuchi, Y. and Kurisu, K. (1999) Effects of Continuous Infusion of PTH on Experimental Tooth Movement in Rats. Journal of Bone and Mineral Research, 14, 546-554. http://dx.doi.org/10.1359/jbmr.1999.14.4.546

[4] Chevalley, T. and Rizzoli, R. (1999) Os et hormones. Influence de l'hormone parathyroidienne sur l'os. La Presse Médicale, 28, 547-553.

[5] Boabaid, F., Berry, J.E., Koh, A.J., Somerman, M.J. and McCcauley, L.K. (2004) The Role of Parathyroid HormoneRelated Protein in the Regulation of Osteoclastogenesis by Cementoblasts. Journal of Periodontology, 75, 1247-1254. http://dx.doi.org/10.1902/jop.2004.75.9.1247

[6] Lee, S.K. and Lorenzo, J.A. (1999) Parathyroid Hormone Stimulates TRANCE and Inhibits Osteoprotegerin Messenger Ribonucleic Acid Expression in Murine Bone Marrow Cultures: Correlation with Osteoclast-Like Cell Formation. Endocrinology, 140, 3552-3561.

[7] Lossdörfer, S., Götz, W., Rath-Deschner, B. and Jäger, A. (2006) Parathyroid Hormone (1-34) Mediates Proliferative and Apoptotic Signaling in Human Periodontal Ligament Cells in Vitro via Protein Kinase C-Dependent and Protein Kinase A-Dependent Pathways. Cell and Tissue Research, 325, 469-479. http://dx.doi.org/10.1007/s00441-006-0198-0

[8] Lossdörfer, S., Yildiz, F., Götz, W., Kheralla, Y. and Jäger, A. (2010) Anabolic Effect of Intermittent PTH (1-34) on the Local Microenvironment during the Late Phase of Periodontal Repair in a Rat Model of Tooth Root Resorption. Clinical Oral Investigations, 14, 89-98. http://dx.doi.org/10.1007/s00784-009-0263-7

[9] Engström, C., Jennings, J., Lundy, M. and Baylink, D.J. (1988) Effect of Bone Matrix-Derived Growth Factors on Skull and Tibia in the Growing Rat. Journal of Oral Pathology, 17, 334-340. http://dx.doi.org/10.1111/j.1600-0714.1988.tb01546.x

[10] Watted, N., Bill, J.S. and Peters, Ch. (2000) A Therapeutic Concept for the Combined Orthodontic Surgical Correction of Angle Class II Deformities with Short-Face Syndrome: Surgical Lengthening of the Lower Face. Clinical Orthodontics and Research, 3, 78-93. http://dx.doi.org/10.1034/j.1600-0544.2000.030204.x

[11] Hullihen, S.R. (1900) Case of Elongation of the under Jaw and Distorsion of the Face and Neck, Caused by a Burn. Dental Cosmos, Philadelphia, 42, 287-293.

[12] Obwegeser, H. and Trauner, R. (1955) Zur Operationstechnik bei der Progenie und anderen Unterkieferanomalien. Dtsch Zahn Mund Kieferheilk 23, H 1 und 2.

[13] Pont, G.D. (1959) L’osteotomia retromolare per la correzione della progenia. Minerva Chirurgica, 18, 1138-1141.

[14] Epker, B.N. (1977) Modification in the Sagittal Osteotomy of the Mandible. Journal of Oral Surgery, 34, 157-159.

[15] Nichols Institute Diagnostic (1998) The Quest Diagnostics Manual Endocrinology, Test Selection and Interpretation. 4th Edition, California.

[16] Lutwak, L., Krook, L., Henrikson, P.A., Uris, R., Whalen, J., Coulston, A. and Lesser, G. (1971) Calcium Deficiency and Human Periodontal Disease. Israel Journal of Medical Sciences, 7, 504-505.

[17] Schulte, W. and Lukas, D. (1992) The Periotest Method. International Dental Journal, 42, 433-440.

[18] Fletcher, P.D., Scopp, I.W. and Hersh, R.A. (1977) Oral Manifestations of Secondary Hyperparathyroidism Related to Long-Term Hemodialysis Therapy. Oral Surgery, Oral Medicine, Oral Pathology, 43, 218-226. http://dx.doi.org/10.1016/0030-4220(77)90159-1

[19] Goldie, R.S. and King, G.J. (1984) Root Resorption and Tooth Movement in Orthodontically Treated, Calcium-Deficient, and Lactating Rats. American Journal of Orthodontics, 85, 424-430.

http://dx.doi.org/10.1016/0002-9416(84)90163-5 
Scientific Research Publishing (SCIRP) is one of the largest Open Access journal publishers. It is currently publishing more than 200 open access, online, peer-reviewed journals covering a wide range of academic disciplines. SCIRP serves the worldwide academic communities and contributes to the progress and application of science with its publication.

Other selected journals from SCIRP are listed as below. Submit your manuscript to us via either submit@scirp.org or Online Submission Portal.
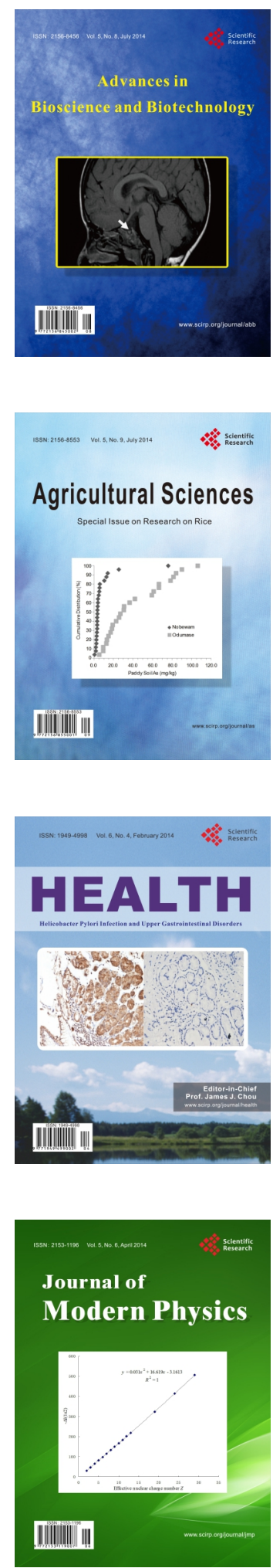
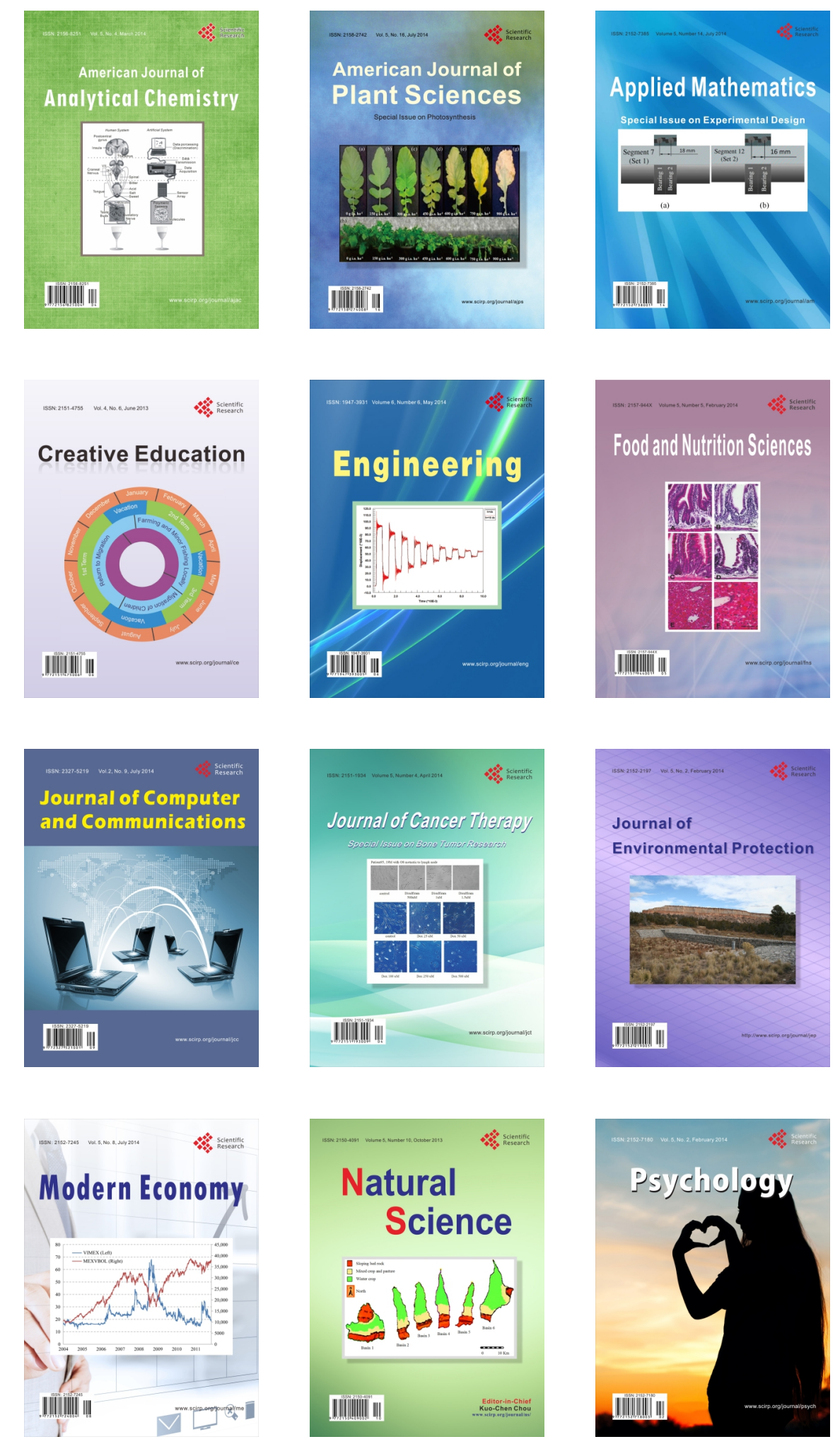